\title{
Testing the Fisher hypothesis in the G-7 countries using I(d) techniques
}

\author{
Guglielmo Maria Caporale $^{\text {a,*, Luis Gil-Alaña }}{ }^{\text {b }}$ \\ ${ }^{\text {a } B r u n e l ~ U n i v e r s i t y ~ L o n d o n, ~ U n i t e d ~ K i n g d o m ~}$ \\ ${ }^{\mathrm{b}}$ University of Navarra, Spain
}

\section{A R T I C L E I N F O}

\section{JEL classification:}

C22

C32

E43

Keywords:

Fisher effect

Fractional integration

Long memory

G7 countries

\begin{abstract}
A B S T R A C T
This paper revisits the Fisher hypothesis concerning the determination of real rates by estimating fractional integration and cointegration models for nominal interest rates and expected inflation in the G7 countries. Two sets of results are obtained under the alternative assumptions of white noise and Bloomfield (1973) autocorrelated errors respectively. The univariate analysis suggests that the differencing parameter is higher than 1 for most series in the former case, whilst the unit root null cannot be rejected for the majority of them in the latter case. The multivariate results imply that there exists a positive relationship, linking nominal interest rates to inflation; however, there is no evidence of the full adjustment of the former to the latter required by the Fisher hypothesis.
\end{abstract}

\section{Introduction}

The long-run behaviour of interest rates is normally analysed using the so-called Fisher relationship (see Fisher, 1930) linking nominal rates and expected inflation and requiring a one-to-one adjustment of the former to the latter, in the absence of which permanent shocks to either inflation or nominal rates have permanent effects on real rates themselves, which is inconsistent with standard models of intertemporal asset pricing as well as superneutrality (to the extent that inflation is a monetary phenomenon), both requiring stationarity of real interest rates. Neoclassical models of dynamic growth also have the property that consumption growth and real rates should both be constant in the steady state.

However, the Fisher relationship is often not supported by the empirical evidence. Many studies, going back to Mishkin (1992), find that the slope coefficient in a regression of inflation against nominal rates is significantly different from one, and the real rates exhibit a unit root. This "paradox" (see Carmichael and Stebbing, 1983) might be due to various reasons, such as not measuring accurately inflationary expectations (see, e.g. Woodward, 1992), overlooking taxation (see Darby, 1975), using short rather than long rates (see Gilbert and Yeoward, 1994), not distinguishing between short- and long-run Fisher effects (see Mishkin, 1992), and finally differences in estimation procedures; in particular, Crowder and Hoffman (1996) and Caporale and Pittis (2004) both showed that using the estimators with the best small sample properties and appropriately computed empirical critical values (rather than the asymptotical ones) produces evidence more supportive of the Fisher effect. All such studies, though, analyse the relationship between interest rates and inflation on the basis of the classic dichotomy between $\mathrm{I}(0)$ and $\mathrm{I}(1)$ variables, which imposes rather restrictive assumptions on the stochastic behaviour of the variables of interest.

By contrast, in the present paper we examine the Fisher effect in the G-7 by adopting a fractional integration/cointegration

\footnotetext{
* Corresponding author.

E-mail address: guglielmo-maria.caporale@brunel.ac.uk (G.M. Caporale).
} 
framework that does not restrict the order of integration d to be 0 or 1 and allows it instead to take any real value; this is clearly a much more general specification allowing for a richer dynamic structure. In particular, consider the following model:

$$
R_{t}=\alpha+\beta \pi_{t+1}+\varepsilon_{t}
$$

where $\mathrm{R}_{\mathrm{t}}$ is the nominal interest rate, $\pi_{\mathrm{t}}$ is the inflation rate (under the implicit assumption of rational expectations, i.e., $\pi_{t+1}=\pi_{t}^{e}$ ), where $\pi_{t}^{e}$ is expected inflation, and $\varepsilon_{\mathrm{t}}$ is an $\mathrm{I}(0)$ error term, defined as a covariance stationary process with a spectral density function that is positive and finite at all frequencies. In this context, if both $\mathrm{R}_{\mathrm{t}}$ and $\pi_{\mathrm{t}}$ are $\mathrm{I}(0)$ variables, standard regression methods can be applied. On the other hand, if they are I(1), a cointegration approach becomes necessary. Unlike in the classical case, we allow these variables to be I(d) with $0<\mathrm{d}<1$ or $\mathrm{d}>1$. First we estimate $\mathrm{d}_{\mathrm{R}}$ and $\mathrm{d}_{\pi}$, i.e., their respective orders of integration, then we make the series stationary $\mathrm{I}(0)$ by differencing them to obtain $\tilde{R}_{t}=(1-L)^{\tilde{d}_{R}} R_{t}$ and $\tilde{\pi}_{t}=(1-L)^{\tilde{d}_{\pi}} \pi_{t+1}$, where $\mathrm{L}$ stands for the lag operator, i.e., L $z_{\mathrm{t}}=\mathrm{z}_{\mathrm{t}-1}$, and $\tilde{d}_{R}$ and $\tilde{d}_{\pi}$ are the estimated orders of integration of the two variables. Then, one can estimate the following regression:

$$
\tilde{R}_{t}=\alpha+\beta \tilde{\pi}_{t}+\varepsilon_{t}, \quad t=1,2,
$$

where the null hypothesis in (2) is:

$$
H_{o}: \quad \beta=1
$$

and both variables are $\mathrm{I}(0)$ as a result of taking differences as appropriate. We also examine the cases where $\tilde{d}_{R}$ and $\tilde{d}_{\pi}$ above are restricted to be either 1 or 0 as in the classical integration and cointegration frameworks for testing the Fisher hypothesis, but also test the order of integration of the errors in (2) to allow for a greater degree of generality as explained in Section 3.

The layout of the paper is the following. Section 2 briefly reviews the literature on the Fisher effect, and more generally on the relationship between nominal interest rates and expected inflation rates. Section 3 outlines the empirical methodology. Section 4 presents the main empirical results. Section 5 offers some concluding remarks.

\section{The Fisher effect: a brief literature review}

Early studies analysed the Fisher effect without considering stationarity issues. These include Fama (1975), Nelson and Schwert (1977) and Garbade and Wachtel (1978). Gilbert and Yeoward (1994) argued that papers using short rates are not informative about the Fisher effect unless short and long rates are strongly correlated; examples are the papers by Summers (1983) and Barsky (1987).

The following generation of studies took a cointegration approach (see, e.g., Mishkin, 1992; Evans and Lewis, 1995; Wallace and Warner, 1993). Engsted (1995) looked at the spread between the long-term (multi-period) interest rate and the one-period inflation estimating a VAR model and found considerable cross-country differences.

Crowder and Wohar (1999) analysed both taxable US Treasury and tax exempt municipal bond interest rates and found a "Darby effect", i.e. evidence that rational agents require nominal rates to adjust in response to movements in "tax-adjusted" expected inflation. Crowder and Hoffman (1996) showed that the choice of estimator is crucial, an issue further investigated by Caporale and Pittis (2004), who provided extensive evidence that if the estimators with the best small sample properties are used and statistical tests are carried out with appropriate empirical critical values the data are supportive of the Fisher effect.

More recently, fractional integration and fractional cointegration techniques have been used to analyse the long memory properties of inflation and interest rates. For example, Shea (1991) investigated the consequences of long memory in interest rates for tests of the expectations hypothesis of the term structure. Phillips (1998) found stationarity but with a high degree of dependence in US interest rates. Tsay (2000) modelled interest rates as AutoRegressive Fractionally Integrated Moving Average (ARFIMA) processes and concluded that the ex-post real interest rate can be well described as a fractionally integrated process. Further evidence of long-memory behaviour in interest rates is provided by Barkoulas and Baum (1997), Meade and Maier (2003), Gil-Alana (2004a,b), Couchman et al. (2006), Gil-Alana and Moreno (2012), Haug (2014), Apergis et al. (2015), Abbritti et al. (2016), etc. As for inflation rates, evidence of long memory has been reported in many papers including Hassler (1993), Delgado and Robinson (1994), Hassler and Wolters (1995), Baillie et al. (1996), Baum et al. (1999), Hyung et al. (2006), Kumar and Okimoto (2007), etc. Lardic and Mignon (2003) found some evidence for the Fisher hypothesis in the G7 countries using semi-parametric I(d) techniques based on log-periodogram regressions; by contrast, no evidence of cointegration between short-term interest rates and inflation was found by Ghazali and Ramlee (2003) by estimating fully parameterised AutoRegressive Fractionally Integrated Moving Average (ARFIMA) models for the same set of countries. Kasman et al. (2006) examined the Fisher relationship with fractional cointegration techniques in 33 developed and developing countries. They found no evidence of cointegration when using classical methods (i.e., Johansen, 1996); however, they found fractional cointegration by using the Geweke and Porter-Hudak (GPH, 1983) log-periodogram approach on the estimated errors from the cointegrating relationship. Similar conclusions were reached in the case of Turkey by Kiran (2013) and for Nigeria by Etuk et al. (2014). The present paper differs from the earlier studies using fractional integration/cointegration methods to test the Fisher hypothesis since, instead of using semi-parametric or fully parametric methods, we adopt a testing procedure for the differencing parameter that relies on non-parametric disturbances. 


\section{Empirical methodology}

\subsection{Univariate analysis}

As mentioned before in the present study we apply fractional integration methods allowing both nominal interest rates and inflation to be $\mathrm{I}(\mathrm{d})$, where $\mathrm{d}$ can be a fractional value. The starting point is the estimation of the differencing parameter $\mathrm{d}$ in:

$$
(1-L)^{d_{i}} x_{t}=v_{t}, \quad t=1,2, \ldots,
$$

where $d_{i}$ is the order of integration for inflation $\left(d_{\pi}\right)$ and interest rates $\left(d_{R}\right), v_{t}$ is an $I(0)$ process as defined above, and in order to allow for deterministic terms $\mathrm{x}_{\mathrm{t}}$ are assumed to be the errors in the model:

$$
y_{t}=\gamma+\delta t+x_{t}, \quad t=1,2, \ldots
$$

where $y_{t}$ is the original series (in our case, interest rates or inflation) and $\gamma$ and $\delta$ stand respectively for the intercept and a linear time trend. For the differencing parameter d we use a testing approach suggested by Robinson (1994) which is based on the Lagrange Multiplier (LM) principle and that, unlike other methods, does not require stationarity and allows d to take any real value. More specifically, it tests the null hypothesis,

$$
H_{o}: \quad\left(d_{i}=\right) d=d_{o},
$$

in (3) where $x_{t}$ can be the errors in a regression model of form:

$$
y_{t}=\beta^{T} z_{t}+x_{t}, \quad t=1,2, \ldots,
$$

where $\beta$ is a (kx1) vector of unknown parameters; $z_{t}$ is a $(k x 1)$ vector of deterministic terms or weakly exogenous terms., and $d_{0}$ can be any real value, including both the stationary $\left(d_{o}<0.5\right)$ and non-stationary $\left(d_{o} \geq 0.5\right)$ cases. This method is based on the Whittle function in the frequency domain (Dahlhaus, 1989) and has several advantages with respect to other methods. Firstly, as just mentioned, it remains valid even for non-stationary processes, and therefore unlike other methods it does not require preliminary differencing (see, e.g., Phillips and Shimotsu, 2005; Lobato and Velasco, 2007; Abadir et al., 2007; etc.): secondly, it has a standard normal limit distribution, unlike most unit root methods where critical values have to be computed numerically case by case; in addition, this limit distribution holds independently of the inclusion of weakly exogenous or deterministic terms in the model, again unlike the unit root case (see, Schmidt and Phillips, 1992); finally, this method is the most efficient one in the Pitman sense against local departures from the null, in the sense that its limit distribution is a standard normal with a non-centrality parameter that is optimal under Gaussianity of the error term. ${ }^{1}$ In Table $1-3$ we display the value of $\mathrm{d}_{\mathrm{o}}$ for which $\mathrm{H}_{\mathrm{o}}$ cannot be rejected (the lowest statistic in absolute value), using a range of values of $d_{o}$ from -1 to 2 with 0.01 increments. In addition, we display the confidence intervals based on this method, noting that classical confidence intervals (including bootstrap type intervals) might be biased in the case of long memory processes, even for large sample sizes (see de Peretti, 2003). Note, however, that the method employed is based on inverting an asymptotic test (Davidson and MacKinnon, 1993), and hence a better performance could be obtained by using inverted bootstrap tests (see, e.g., de Peretti and Siani, 2002, Conti et al., 2008; Arteche and Orbe, 2016; etc.). ${ }^{2,3}$

Note that under the null hypothesis, the model in (3) and (4) becomes:

$$
y_{t}=\gamma+\delta t+x_{t} ; \quad(1-L)^{d_{o}} x_{t}=u_{t} ; \quad t=1,2, \ldots
$$

which can be written as a single equation:

$$
\tilde{y}_{t}=\gamma \tilde{1}_{t}+\delta \tilde{t}_{t}+u_{t} ; \quad t=1,2, \ldots
$$

where $\tilde{y}_{t}=(1-L)^{d_{o}} y_{t} ; \tilde{1}_{t}=(1-L)^{d_{o}} 1$, and $\tilde{t}_{t}=(1-L)^{d_{o}} t$, and since $\mathrm{u}_{\mathrm{t}}$ is $\mathrm{I}(0)$ by construction, standard t-tests can be carried out for $\gamma$ and $\delta$ in (7). ${ }^{4}$

\subsection{Multivariate analysis}

To analyse the relationship between the two variables we first run a regression of the following form:

$$
(1-L)^{d_{R}} R_{t}=\alpha+\beta(1-L)^{d_{\pi}} \pi_{t}+u_{t}, \quad t=1,2,
$$

\footnotetext{
${ }^{1}$ See Robinson (1994) for more details. The Fortran codes used for the empirical analysis are available from the authors upon request.

${ }^{2}$ As mentioned in the conclusions, this issue is left for future work.

${ }^{3}$ Alternative methods also based on the likelihood function may be employed. For instance, Lobato and Velasco (2007) proposed a Wald test which is based on a very similar set-up, though clearly it requires a consistent estimate of d, thus being computationally more expensive.

${ }^{4}$ Note that in case of $d_{o}=1$ the time trend becomes a constant and for $d_{o}<1$ it disappears in the long run.
} 
Table 1

Estimates of $d_{\pi}$ and $95 \%$ confidence bands for the inflation series.

\begin{tabular}{|c|c|c|c|}
\hline & No deterministic terms & An intercept & A linear time trend \\
\hline \multicolumn{4}{|c|}{ i) Uncorrelated (white noise) errors } \\
\hline CANADA & $0.95(0.82,1.12)$ & $0.97(0.83,1.15)$ & $0.97(0.83,1.15)$ \\
\hline FRANCE & $1.15(1.04,1.29)$ & $1.25(1.13,1.41)$ & $1.25(1.13,1.41)$ \\
\hline GREAT BRITAIN & $1.19(1.07,1.35)$ & $1.19(1.06,1.35)$ & $1.19(1.06,1.35)$ \\
\hline GERMANY & $1.04(0.93,1.22)$ & $0.96(0.86,1.09)$ & $0.96(0.86,1.09)$ \\
\hline ITALY & $1.20(1.09,1.34)$ & $1.25(1.15,1.38)$ & $1.25(1.15,1.38)$ \\
\hline JAPAN & $1.18(1.05,1.36)$ & $1.18(1.06,1.36)$ & $1.18(1.06,1.36)$ \\
\hline U.S.A. & $1.23(1.07,1.44)$ & $1.40(1.20,1.67)$ & $1.40(1.20,1.67)$ \\
\hline \multicolumn{4}{|c|}{ ii) Autocorrelated (Bloomfield) errors } \\
\hline CANADA & $0.77(0.51,1.09)$ & $0.73(0.43,1.11)$ & $0.74(0.43,1.11)$ \\
\hline FRANCE & $1.11(0.87,1.46)$ & $1.18(0.88,1.52)$ & $1.19(0.88,1.54)$ \\
\hline GREAT BRITAIN & $1.12(0.89,1.45)$ & $1.12(0.86,1.54)$ & $1.12(0.88,1.54)$ \\
\hline GERMANY & $1.12(0.90,1.46)$ & $1.18(0.93,1.56)$ & $1.18(0.93,1.56)$ \\
\hline ITALY & $1.24(1.00,1.54)$ & $1.40(1.08,1.77)$ & $1.40(1.08,1.79)$ \\
\hline JAPAN & $0.99(0.76,1.30)$ & $0.99(0.76,1.31)$ & $0.99(0.76,1.31)$ \\
\hline U.S.A. & $0.83(0.57,1.15)$ & $0.69(0.46,1.06)$ & $0.70(0.42,1.06)$ \\
\hline
\end{tabular}

In bold the most adequate specification according to the t-values for the deterministic terms. In parenthesis the $95 \%$ confidence bands of the nonrejection values using Robinson's (1994) tests.

$$
(1-L)^{d_{u}} u_{t}=\xi_{t}, \quad t=1,2
$$

estimating simultaneously $\alpha, \beta$ and $d_{u}$, for different cases. In particular, we examine three cases: i) imposing a priori $d_{R}=d_{\pi}=1$ in (8); ii) imposing a priori $d_{R}=d_{\pi}=0$ in (8); (note that these are the most standard cases examined in the literature), and iii) using for $d_{R}$ and $d_{\pi}$ the estimated values obtained previously using the univariate methods, first without any restrictions and then setting $d_{u}$ in (8) equal to 0 . Note that in the case of the estimated values for $d_{r}$ and $d_{\pi}$ in equation (8) there is no obvious economic interpretation for the fractionally differenced interest rate and inflation rate since these are numerical artifacts to produce $\mathrm{I}(0)$ variables. We assume the $\mathrm{I}(0)$ error term $\xi_{\mathrm{t}}$ in (8) to be in turn uncorrelated (white noise) and autocorrelated, in the latter case using the exponential spectral model of Bloomfield (1973). This is a non-parametric model, in the sense that it is only implicitly defined in terms of its spectral density function, which is given by:

$$
f(\lambda ; \tau)=\frac{\sigma^{2}}{2 \pi} \exp \left(2 \sum_{r=1}^{m} \tau_{r} \cos (\lambda r)\right),
$$

where $\sigma^{2}$ is the variance of the error term and $m$ indicates the last of the Fourier frequencies which is associated with the short-run dynamics. Bloomfield (1973) showed that the spectral density function of a highly parameterised ARMA process can be well approximated by (10); this model produces autocorrelations decaying exponentially as in the AR(MA) case and is stationary for its entire range of values. Moreover, it has been shown that it fits extremely well in the context of fractional integration (Gil-Alana, 2004c, 2008) and avoid the problem of misspecification inherent in the ARMA modelling approach that might produce an inconsistent estimate of d. As mentioned before, the methodology employed is based on Robinson (1994) since his procedure allows to include (weakly) exogenous variables in the regression model without affecting the limiting behaviour.

\section{Empirical results}

The series used for the analysis are the long-term (10 year) government bond yield for the nominal interest rate and the first differences of the log CPI series for inflation in the G7 countries, monthly, for the time period January 2006-December 2016 (including all goods); therefore we have 132 observations, which might be a short span to detect long memory effects; nevertheless, several Monte Carlo experiments conducted in Robinson (1994) showed that his tests perform relatively well in finite samples, and various empirical applications based on this method (see, e.g., Gil-Alana and Robinson, 1997) were conducted with even fewer observations. ${ }^{5}$ The data source is the St. Louis Federal Reserve Bank database, and plots of the two series are displayed in Fig. 1. Nominal interest rates appear to decline in all countries, and inflation is generally lower in the second half of subsample, Japan being the single exception. Despite the monthly frequency of the data, seasonality did not appear to be an issue. Seasonal (monthly) dummies were found to be insignificant, and similarly in seasonal autoregressions the coefficients were very close to 0 in all cases.

\footnotetext{
${ }^{5}$ When using the critical values computed in Gil-Alana (2000) for finite samples, the results were almost identical to those reported here based on the asymptotic values.
} 


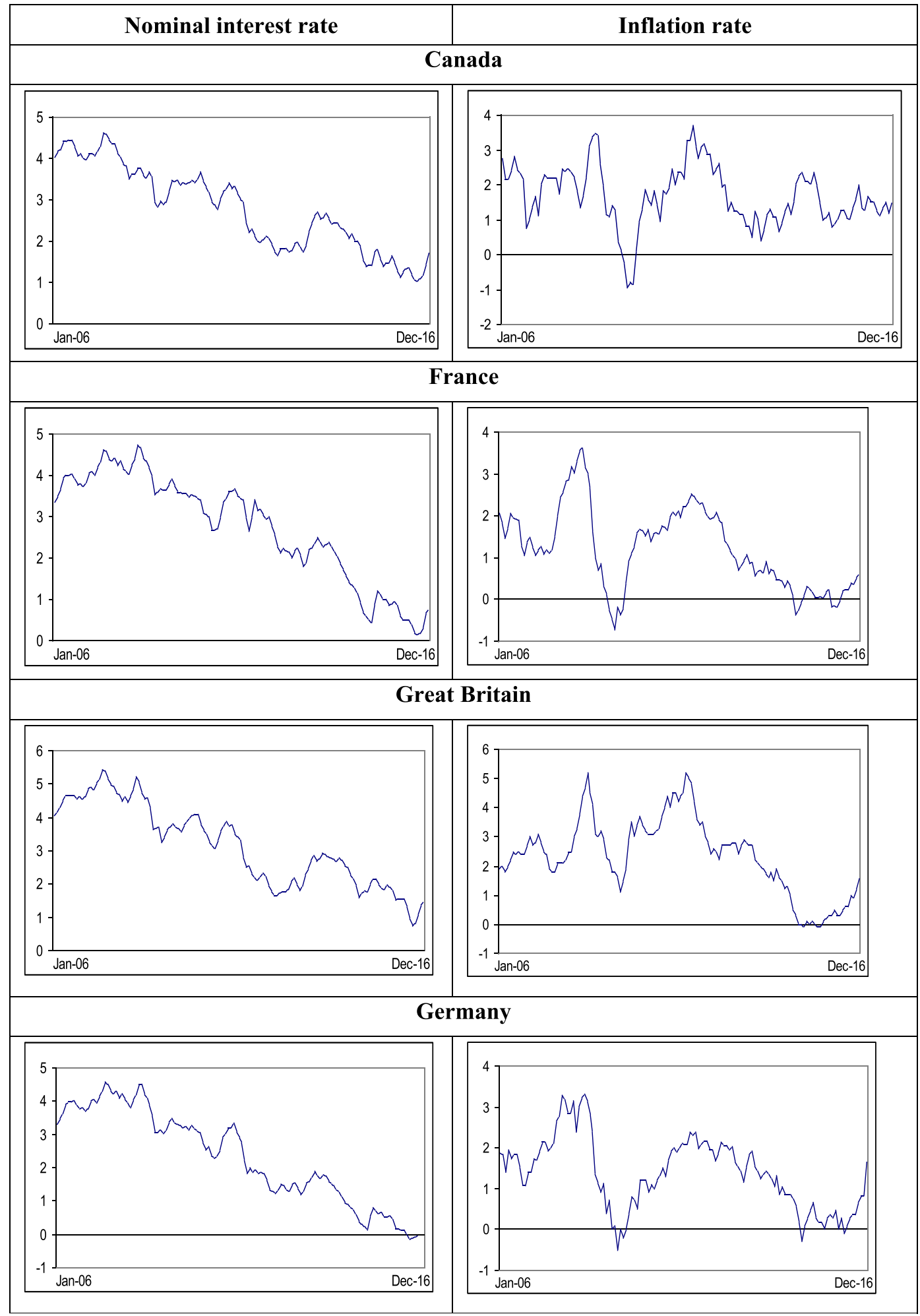

Fig. 1. Time series plots. 


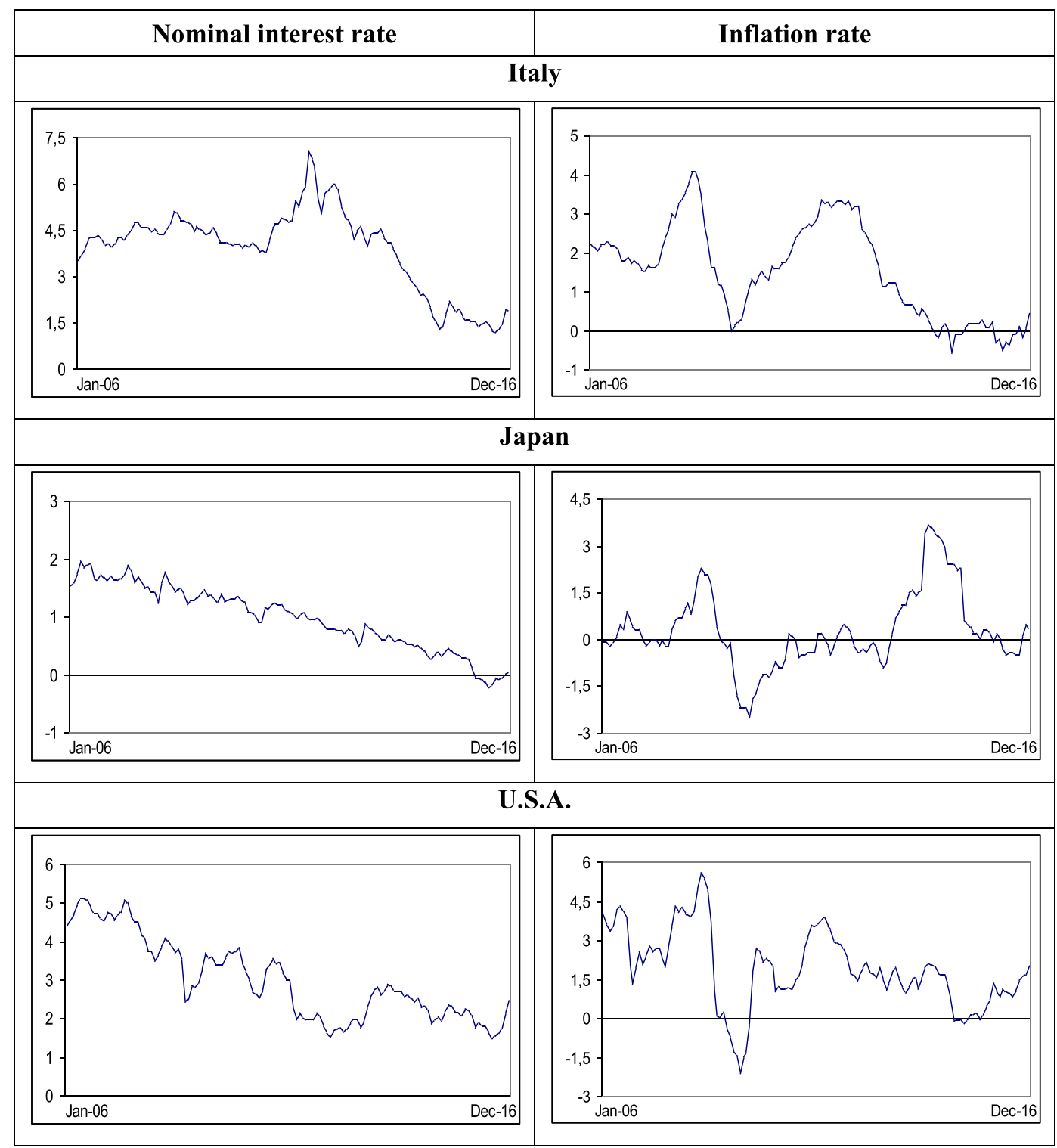

Fig. 1. . (continued).

\subsection{Univariate results}

We start with the univariate analysis. Tables 1 and 2 display the estimates of $d$ (along with the 95\% bands corresponding to their nonrejection values using Robinson's (1994) method), for inflation and interest rates respectively. Following the standard parameterisation for unit root models (Schmidt and Phillips, 1992) we include a linear time trend in the model, and consider the three cases of i) no deterministic terms (i.e., $\gamma=\delta=0$ a priori in (4)), ii) an intercept (i.e., $\gamma$ unknown and $\delta=0$ a priori) and iii) an intercept with a linear time trend (both $\gamma$ and $\delta$ unknown and estimated from the data). ${ }^{6}$ The estimated model is the one given by equation (6) with uncorrelated and Bloomfield (1973) errors $\left(u_{t}\right)$ in turn. In the case of inflation rates, a time trend is required only for the US with autocorrelated errors, and no deterministic terms are required for Japan. As mentioned before, the deterministic trends were selected on the basis of the t-values for the coefficients of the differenced model, first with a specification with an intercept and a time trend, then with an intercept only, and finally with no deterministic terms. Non-linear deterministic trends of the form proposed in Cuestas and Gil-Alana (2016) were rejected in all cases.

\footnotetext{
${ }^{6}$ Note that, given the arguments provided in the previous section (eq. (6)) the time trend disappears in the unit root case $(d=1)$, and if $u_{t}$ is a white noise, $\mathrm{y}_{\mathrm{t}}$ becomes a random walk with a drift.
} 
Table 2

Estimates of $d_{R}$ and $95 \%$ confidence bands for the interest rate series.

\begin{tabular}{|c|c|c|c|}
\hline & No deterministic terms & An intercept & A linear time trend \\
\hline \multicolumn{4}{|c|}{ i) Uncorrelated (white noise) errors } \\
\hline CANADA & $1.11(0.98,1.26)$ & $1.20(1.03,1.42)$ & $1.20(1.02,1.42)$ \\
\hline FRANCE & $1.12(1.01,1.27)$ & $1.23(1.06,1.46)$ & $1.23(1.06,1.46)$ \\
\hline GREAT BRITAIN & $1.09(0.98,1.24)$ & $1.29(1.12,1.51)$ & $1.29(1.12,1.51)$ \\
\hline GERMANY & $1.10(0.99,1.26)$ & $1.25(1.09,1.48)$ & $1.25(1.09,1.47)$ \\
\hline ITALY & $1.10(0.99,1.25)$ & $1.14(1.02,1.35)$ & $1.15(1.02,1.34)$ \\
\hline JAPAN & $1.03(0.92,1.18)$ & $0.84(0.74,1.03)$ & $0.78(0.56,1.03)$ \\
\hline U.S.A. & $1.12(1.00,1.27)$ & $1.17(0.99,1.38)$ & $1.17(0.99,1.38)$ \\
\hline \multicolumn{4}{|c|}{ ii) Autocorrelated (Bloomfield) errors } \\
\hline CANADA & $1.02(0.83,1.32)$ & $0.78(0.63,1.13)$ & $0.72(0.41,1.13)$ \\
\hline FRANCE & $1.09(0.90,1.38)$ & $0.81(0.70,1.06)$ & $0.73(0.49,1.06)$ \\
\hline GREAT BRITAIN & $1.07(0.88,1.42)$ & $0.82(0.63,1.13)$ & $0.77(0.50,1.13)$ \\
\hline GERMANY & $1.03(0.85,1.34)$ & $0.85(0.72,1.18)$ & $0.80(0.53,1.17)$ \\
\hline ITALY & $1.11(0.92,1.37)$ & $0.93(0.79,1.16)$ & $0.92(0.78,1.14)$ \\
\hline JAPAN & $1.00(0.81,1.31)$ & $0.66(0.58,0.78)$ & $0.20(0.03,0.48)$ \\
\hline U.S.A. & $1.05(0.84,1.38)$ & $0.73(0.58,1.12)$ & $0.71(0.49,1.12)$ \\
\hline
\end{tabular}

In bold the most adequate specification according to the t-values for the deterministic terms. In parenthesis the $95 \%$ confidence bands of the nonrejection values using Robinson's (1994) tests.

In addition to the $95 \%$ confidence intervals of the non-rejection values of $\mathrm{d}_{\mathrm{o}}$ obtained using the tests of Robinson (1994) we also report the value of $d_{o}$ with the lowest statistic in absolute value, this being an approximation to the Whittle estimate $d$ in the frequency domain which is the optimised function with the tests of Robinson (1994). The values of $d$ under the assumption of white noise errors are significantly higher than 1 , and evidence of a unit root (i.e., $\mathrm{d}=1$ ) is only obtained in the cases of Canada and Germany. With autocorrelation in $u_{t}$, evidence of a unit root is found in all cases except for Italy where the estimated value of $d$ is much higher than 1 .

Moving on to interest rates, a time trend seems to be appropriate for Japan with uncorrelated errors, and in all cases except Italy with autocorrelated ones. With a white noise process for $\mathrm{u}_{\mathrm{t}}$, the estimated values of $\mathrm{d}$ are much higher than 1 in all cases except for Japan and the US where the unit root null cannot be rejected. Under the assumption of autocorrelation, we obtain evidence of unit roots in all cases except for Japan, where the series seems to be stationary (i.e. with $\mathrm{d}<0.5$ ).

Table 3 summarises the estimates of $d$ with autocorrelation for $u_{t}$, in (5), a more appropriate assumption given the results of the diagnostic tests carried out on the residuals(not reported). ${ }^{7}$ The unit root null is almost never rejected. The only exceptions are the inflation rate in Italy, with an order of integration much higher than 1, and interest rates in Japan, with a value significantly smaller than 1. However, in the case of Italy the confidence bands for the two variables overlap suggesting that the estimated values are not significantly different.

\subsection{Multivariate results}

Tables 4-6 show the estimated coefficients from equations (8) and (9) under three different assumptions, specifically, in Table $4 d_{R}$ and $d_{\pi}$ are both set equal to 1 ; in Table 5 , despite the evidence from Table 3 , both variables are assumed to be I( 0 ), and therefore $\mathrm{d}_{\mathrm{R}}=\mathrm{d}_{\pi}=0$, while in Table 6 the estimated values from Table 3 are used for $\mathrm{d}_{\mathrm{R}}$ and $\mathrm{d}_{\pi}$, implying in all these cases that the values of $\tilde{R}_{t}$ and $\tilde{\pi}_{t}$ are observed, and then avoiding the issue of unbalanced cointegration as stated in Sun and Phillips (2004).

In Table 4, we impose $d_{R}=d_{\pi}=1$ - this is a common assumption in the empirical literature that usually treats interest rates and inflation as being non-stationary I(1). Therefore, both variables in the regression model, $\tilde{R}_{t}$ and $\tilde{\pi}_{t}$ are expected to be I(0). In the case of

Table 3

Estimates of the orders of integration for each series.

\begin{tabular}{|c|c|c|}
\hline & Inflation rates $\left(\mathrm{d}_{\pi}\right)$ & Interest rates $\left(d_{R}\right)$ \\
\hline CANADA & $0.73(0.43,1.11)$ & $0.72(0.41,1.13)$ \\
\hline FRANCE & $1.18(0.88,1.52)$ & $0.73(0.49,1.06)$ \\
\hline GREAT BRITAIN & $1.12(0.86,1.54)$ & $0.77(0.50,1.13)$ \\
\hline GERMANY & $1.18(0.93,1.56)$ & $0.80(0.53,1.17)$ \\
\hline ITALY & $1.40(1.08,1.77)$ & $0.93(0.79,1.16)$ \\
\hline JAPAN & $0.99(0.76,1.30)$ & $0.20(0.03,0.48)$ \\
\hline U.S.A. & $0.70(0.42,1.06)$ & $0.71(0.49,1.12)$ \\
\hline
\end{tabular}

In bold, evidence of unit roots at the $5 \%$ level.

\footnotetext{
${ }^{7}$ We basically conduct tests of no autocorrelation in the set-up with white noise errors. If this hypothesis is rejected, we choose the non-parametric autocorrelated model of Bloomfield (1973).
} 
Table 4

Estimates of $d_{u}, \alpha$ and $\beta$ with $d_{R}=d_{\pi}=1$.

\begin{tabular}{|c|c|c|c|}
\hline & $\mathrm{d}_{\mathrm{u}}(95 \%$ conf. band $)$ & $\alpha$ (t-value) & $\beta$ (t-value) \\
\hline \multicolumn{4}{|c|}{ i) Uncorrelated (white noise) errors } \\
\hline CANADA & $0.19(0.03,0.40)$ & $-0.008(-0.28)$ & $0.04(1.48)$ \\
\hline FRANCE & $0.20(0.05,0.42)$ & $-0.005(-0.16)$ & $0.12(1.99)$ \\
\hline GREAT BRITAIN & $0.26(0.10,0.48)$ & $-0.006(-0.14)$ & $0.14(2.95)$ \\
\hline GERMANY & $0.24(0.06,0.46)$ & $-0.01(-0.26)$ & $0.03(0.77)$ \\
\hline ITALY & $0.13(0.02,0.35)$ & $-0.006(-0.16)$ & $0.06(0.65)$ \\
\hline JAPAN & $-0.18(-0.33,0.05)$ & $-0.01(-3.39)$ & $-0.004(-0.22)$ \\
\hline JAPAN $(*)$ & $-0.19(-0.34,0.03)$ & $-0.01(-3.16)$ & $-0.002(-0.64)$ \\
\hline U.S.A. & $0.14(-0.01,0.34)$ & $-0.006(-0.20)$ & $0.09(2.54)$ \\
\hline \multicolumn{4}{|c|}{ ii) Autocorrelated (Bloomfield) errors } \\
\hline CANADA & $-0.24(-0.49,0.16)$ & $-0.02(-4.54)$ & $0.06(2.13)$ \\
\hline FRANCE & $-0.19(-0.35,0.12)$ & $-0.02(-3.48)$ & $0.14(2.94)$ \\
\hline GREAT BRITAIN & $-0.17(-0.37,0.12)$ & $-0.02(-3.18)$ & $0.16(3.85)$ \\
\hline GERMANY & $-0.16(-0.35,0.19)$ & $-0.02(-3.90)$ & $0.09(2.13)$ \\
\hline ITALY & $-0.11(-0.28,0.12)$ & $-0.01(-0.89)$ & $0.19(2.22)$ \\
\hline JAPAN & $-0.54(-0.67,-0.29)$ & $-0.01(-16.09)$ & $0.007(0.52)$ \\
\hline JAPAN $(*)$ & $-0.55(-0.69,-0.30)$ & $-0.01(-13.80)$ & $-0.003(-1.98)$ \\
\hline U.S.A. & $-0.19(-0.44,0.20)$ & $-0.01(-2.20)$ & $0.09(3.11)$ \\
\hline
\end{tabular}

In bold, statistically significant positive coefficients at the $5 \%$ level.

Table 5

Estimates of $d_{u}$, $\alpha$ and $\beta$ with $d_{R}=d_{\pi}=0$.

\begin{tabular}{|c|c|c|c|}
\hline & $\mathrm{d}_{\mathrm{u}}(95 \%$ conf. band $)$ & $\alpha$ (t-value) & $\beta$ (t-value) \\
\hline \multicolumn{4}{|c|}{ i) Uncorrelated (white noise) errors } \\
\hline CANADA & $1.19(1.02,1.41)$ & $3.86(22.33)$ & 0.04 (1.49) \\
\hline FRANCE & $1.20(1.04,1.43)$ & $3.04(14.93)$ & $0.12(2.01)$ \\
\hline GREAT BRITAIN & $1.26(1.10,1.48)$ & 3.77 (20.42) & $0.14(2.96)$ \\
\hline GERMANY & $1.17(1.02,1.37)$ & $3.16(17.61)$ & $0.05(1.12)$ \\
\hline ITALY & $1.13(0.97,1.35)$ & $3.36(10.44)$ & $0.06(0.66)$ \\
\hline JAPAN & $0.84(0.73,1.04)$ & $1.56(16.82)$ & $-0.00(-0.30)$ \\
\hline U.S.A. & $1.13(0.98,1.34)$ & $4.01(15.88)$ & $0.09(2.57)$ \\
\hline \multicolumn{4}{|c|}{ ii) Autocorrelated (Bloomfield) errors } \\
\hline CANADA & $0.82(0.66,1.18)$ & $3.85(23.44)$ & $0.06(2.19)$ \\
\hline FRANCE & $0.83(0.71,1.10)$ & $3.07(16.69)$ & $0.16(3.19)$ \\
\hline GREAT BRITAIN & $0.85(0.68,1.12)$ & $3.78(21.14)$ & $0.16(3.91)$ \\
\hline GERMANY & $0.88(0.74,1.19)$ & 3.16 (17.97) & $0.09(2.13)$ \\
\hline ITALY & $0.88(0.72,1.14)$ & $3.13(10.92)$ & $0.20(2.44)$ \\
\hline JAPAN & $0.65(0.57,0.78)$ & $1.50(19.51)$ & $-0.003(-0.17)$ \\
\hline U.S.A. & $0.79(0.60,1.16)$ & $4.05(17.92)$ & $0.10(3.22)$ \\
\hline
\end{tabular}

In bold, statistically significant positive coefficients at the $5 \%$ level.

Table 6

Estimates of $d_{u}, \alpha$ and $\beta$ with $d_{R}$ and $d_{\pi}$ freely estimated from the data.

\begin{tabular}{|c|c|c|c|}
\hline & $\mathrm{d}_{\mathrm{u}}(95 \%$ conf. band $)$ & $\alpha$ (t-value) & $\beta$ (t-value) \\
\hline \multicolumn{4}{|c|}{ i) Uncorrelated (white noise) errors } \\
\hline CANADA & $0.37(0.26,0.93)$ & $0.77(4.40)$ & $0.35(6.36)$ \\
\hline FRANCE & $0.42(0.32,0.99)$ & $0.52(4.03)$ & $0.51(7.32)$ \\
\hline GREAT BRITAIN & $0.30(0.21,0.45)$ & $0.26(2.55)$ & $0.54(6.74)$ \\
\hline GERMANY & $0.28(0.18,0.42)$ & $0.18(2.07)$ & $0.32(4.71)$ \\
\hline ITALY & $0.22(0.11,0.38)$ & $0.10(1.28)$ & $0.55(6.02)$ \\
\hline JAPAN & $0.61(0.54,0.83)$ & $1.15(12.84)$ & $-0.01(-0.58)$ \\
\hline U.S.A. & $0.46(0.32,0.95)$ & $0.74(3.89)$ & $0.39(7.93)$ \\
\hline \multicolumn{4}{|c|}{ ii) Autocorrelated (Bloomfield) errors } \\
\hline CANADA & $0.25(0.08,0.61)$ & $0.23(2.52)$ & $0.38(6.72)$ \\
\hline FRANCE & $0.32(0.19,0.55)$ & $0.28(3.08)$ & $0.53(7.42)$ \\
\hline GREAT BRITAIN & $0.27(0.10,0.52)$ & $0.21(2.35)$ & $0.54(6.84)$ \\
\hline GERMANY & $0.23(0.09,0.47)$ & $0.12(2.34)$ & $0.34(4.79)$ \\
\hline ITALY & $0.15(-0.01,0.39)$ & $0.05(1.00)$ & $0.56(6.06)$ \\
\hline JAPAN & $0.51(0.45,0.60)$ & $0.92(13.46)$ & $-0.01(-0.49)$ \\
\hline U.S.A. & $0.31(0.11,0.50)$ & $0.29(2.62)$ & $0.39(8.25)$ \\
\hline
\end{tabular}

In bold, statistically significant positive coefficients at the $5 \%$ level. 
Japan, given the stationarity of interest rates implied by Table 3 , we also display the results with $d_{R}=0$ and $d_{\pi}=1$. It can be seen that with uncorrelated errors (now $\xi_{t}$ in (9)) (Table $4 i$ ), the estimated value of $d_{u}$ is significantly positive for all the countries except Japan and USA, while $\beta$ is only significant for France, Great Britain and the USA, whilst with autocorrelation in $\varepsilon_{t}$, the estimated value of $d_{u}$ is smaller than in the previous case, and the I(0) hypothesis for the error cannot be rejected for any country except Japan and the US, and the estimated value of $\beta$ is significantly positive in all cases except Japan. According to these regression results, changes in interest rates and changes in expected inflation are positively correlated in all cases except for Japan.

In Table 5 we assume that $\mathrm{d}_{\mathrm{R}}=\mathrm{d}_{\pi}=0$, i.e. we run the regression model using the original data without taking differences, as in the Fisher relationship. In the autocorrelation case, we cannot reject the null that the estimated errors are I(1) with the only exception of Japan, where $d_{u}$ is found to be smaller than 1 . Note that in this case, given the I(1) evidence provided by the univariate analysis, an estimated value of $d_{u}$ smaller than 1 implies fractional cointegration, whilst non-fractional cointegration holds if $d_{u}=0$. Once more, all the estimated values of $\beta$ are significantly positive except in the case of Japan, though they are rather small. However, the finding on nonstationarity (or I(1) behaviour) of the errors in this model implies that the relations are spurious and thus invalid.

In Table 6 we take differences using the estimated values of $\mathrm{d}$ reported in Table 3. Without correlation in the error term, the estimated value of $d_{u}$ is found to be positive in all cases, ranging from 0.22 (Italy) to 0.61 (Japan), whilst with autocorrelated errors the $\mathrm{I}(0)$ hypothesis cannot be rejected for Italy, $\mathrm{d}$ being positive in the remaining cases and ranging from 0.23 (Germany) to 0.51 (Japan). The estimates of $\beta$ are very similar in the two cases of white noise and autocorrelated errors, and the values are substantially higher than previously and positive, except for Japan.

Finally, in Table 7, we compare the estimates of $\beta$ with those obtained when imposing $d_{u}=0$ in (9). They are generally higher than in the previous cases, especially when $\mathrm{d}_{R}=\mathrm{d}_{\pi}=0$. In fact, in the $\mathrm{I}(0)$ case, even the hypothesis $\beta=1$ cannot be rejected for some countries (France, Germany and Italy). However, it should be noted that this specification is incorrect since the null hypothesis of $\mathrm{d}=0$ is rejected in favour of $\mathrm{d}>0$ in all the cases shown in Table 5.

Overall, the evidence based on our preferred model (Table 6ii) suggests that there exists a positive relationship between the (filtered) nominal interest rates and inflation, since the $\beta$ coefficient is positive; however, it is statistically different from 1 (more precisely, it is smaller). ${ }^{8}$ Therefore, we do not find evidence of the full adjustment neither of nominal rates to inflation required by the Fisher hypothesis nor with the filtered data. The specificity of the results for Japan might reflect the well-known liquidity trap characterising this country, since its monetary policy was based on a very low interest rate as far back as 1995, which was followed by a zero interest rate since 1999, and Quantitative Easing (QE) since 2001, well before all the other countries where QE was introduced in response to the global financial crisis of 2007-8. It should be noted that the period analysed includes Quantitative Easing (QE); this increases inflation, but its impact on real rates is not clear since risk premia might decrease and therefore real rates could fall as well as rise. It also includes frequent shifts in inflation which might produce spurious evidence against the Fisher relationship; these disappear when they are taken explicitly into account in a Markov-switching framework (see Evans and Lewis, 1995). Modelling such switches is beyond the scope of the present study, and therefore our results should be taken with caution.

Table 7

Estimates of $\alpha$ and $\beta$ in equations (7) and (8) with $d$ imposed to be equal to 0 .

\begin{tabular}{|c|c|c|c|c|c|c|}
\hline & \multicolumn{2}{|c|}{$\mathrm{d}_{\mathrm{R}}=\mathrm{d}_{\pi}=1$} & \multicolumn{2}{|c|}{$\mathrm{d}_{\mathrm{R}}=\mathrm{d}_{\pi}=0$} & \multicolumn{2}{|c|}{$\underline{\mathrm{d}_{\mathrm{R}} \text { and } \mathrm{d}_{\pi} \text { estimated }}$} \\
\hline & $\alpha$ & $\beta$ & $\alpha$ & $\beta$ & $\alpha$ & $\beta$ \\
\hline CANADA & $\begin{array}{l}-0.01 \\
(-1.30)\end{array}$ & $\begin{array}{l}0.05 \\
(1.75)\end{array}$ & $\begin{array}{l}2.20 \\
(33.49)\end{array}$ & $\begin{array}{l}0.33 \\
(9.57)\end{array}$ & $\begin{array}{l}0.04 \\
(1.66)\end{array}$ & $\begin{array}{l}0.42 \\
(7.30)\end{array}$ \\
\hline FRANCE & $\begin{array}{l}-0.01 \\
(-1.31)\end{array}$ & $\begin{array}{l}0.13 \\
(2.44)\end{array}$ & $\begin{array}{l}1.71 \\
(34.14)\end{array}$ & $\begin{array}{l}0.84^{*} \\
(25.92)\end{array}$ & $\begin{array}{l}0.04 \\
(1.89)\end{array}$ & $\begin{array}{l}0.58 \\
(6,90)\end{array}$ \\
\hline GR. BRITAIN & $\begin{array}{l}-0.01 \\
(-1.38)\end{array}$ & $\begin{array}{l}0.15 \\
(3.47)\end{array}$ & $\begin{array}{l}2.14 \\
(29.40)\end{array}$ & $\begin{array}{l}0.42 \\
(15.62)\end{array}$ & $\begin{array}{l}0.04 \\
(1.70)\end{array}$ & $\begin{array}{l}0.60 \\
(6.90)\end{array}$ \\
\hline GERMANY & $\begin{array}{l}-0.02 \\
(-1.84)\end{array}$ & $\begin{array}{l}0.06 \\
(1.49)\end{array}$ & $\begin{array}{l}1.12 \\
(13.62)\end{array}$ & $\begin{array}{l}0.87^{*} \\
(17.29)\end{array}$ & $\begin{array}{l}0.01 \\
(0.60)\end{array}$ & $\begin{array}{l}0.39 \\
(4.92)\end{array}$ \\
\hline ITALY & $\begin{array}{l}-0.01 \\
(-0.52)\end{array}$ & $\begin{array}{l}0.12 \\
(1.49)\end{array}$ & $\begin{array}{l}2.50 \\
(49.38)\end{array}$ & $\begin{array}{l}0.91 * \\
(35.24)\end{array}$ & $\begin{array}{l}0.02 \\
(0.75)\end{array}$ & $\begin{array}{l}0.59 \\
(5.94)\end{array}$ \\
\hline JAPAN & $\begin{array}{l}-0.01 \\
(-1.40)\end{array}$ & $\begin{array}{l}-0.01 \\
(-0.54)\end{array}$ & $\begin{array}{l}1.00 \\
(52.26)\end{array}$ & $\begin{array}{l}-0.09 \\
(-5.95)\end{array}$ & $\begin{array}{l}0.37 \\
(20.29)\end{array}$ & $\begin{array}{l}0.02 \\
(0.52)\end{array}$ \\
\hline U.S.A. & $\begin{array}{l}-0.01 \\
(-0.74)\end{array}$ & $\begin{array}{l}0.09 \\
(2.81)\end{array}$ & $\begin{array}{l}2.41 \\
(51.07)\end{array}$ & $\begin{array}{l}0.30 \\
(5.67)\end{array}$ & $\begin{array}{l}0.06 \\
(2.13)\end{array}$ & $\begin{array}{l}0.37 \\
(8.64)\end{array}$ \\
\hline
\end{tabular}

In bold, significant positive coefficients at the $5 \%$ level. ${ }^{*}$ : Evidence of $\beta=1$ at the $5 \%$ level. The values in parenthesis are the t-values of the corresponding estimated coefficients.

\footnotetext{
${ }^{8}$ Note, however, that some biases may exist, coming from the d-estimates, or alternatively from the estimation in (8). With this in mind we carry out various diagnostic tests on the residuals, including tests of no serial correlation (Durbin, 1970, Godfrey, 1978a,b) and homoscedasticity, Koenker, 1981); these support the fractional specification.
} 


\section{Conclusions}

This paper revisits the Fisher hypothesis in the G7 countries using regression models that include long memory and fractional integration and therefore are more general than the standard ones based on integer degrees of differentiation, and thus on the classical I(0)/I(1) dichotomy. Two sets of results are produced under the alternative assumptions of uncorrelated and autocorrelated errors.

The univariate analysis suggests that the differencing parameter is higher than 1 for most series in the case with uncorrelated errors, whilst the unit root null cannot be rejected for the majority of them under a very general form of non-parametric autocorrelation. The multivariate results imply that there exists a positive relationship, linking nominal interest rates to inflation; however, the Fisher hypothesis is rejected since there is no full adjustment of the former to the latter. Country-specific factors such as the monetary policy rules adopted might account for differences across countries. For instance, as already mentioned, the contractionary monetary policy during the economic slump going back to 1995 might be the reason for the different findings in the case of Japan. As for economies such as Germany, France and Italy, although they are all members of the same monetary union, domestic factors have clearly continued to play an important role in driving interest rates.

However, one should be cautious with the results presented in this study: the sample period examined (January 2006-December 2016) is likely to include structural breaks reflecting the general turbulence between 2007 and 2012 (the sub-prime mortgages and European debts crises); breaks or regime-switching models are in fact very much related with fractional integration (Diebold and Inoue, 2001; Granger and Hyung, 2004). Future work will examine such issues.

It will also address the problem described in Sun and Phillips (2004), namely that of the data quality when an ex-post variable is used as a proxy of an ex-ante variable. Because the former is a realized measure of the unobserved latter variable incorporating unexpected short run shocks, the integration orders are biased downward. Three solutions are possible: finding a better proxy of the ex-ante variable, estimating the bias using asymptotic formulas, and modelling the short memory perturbation in the joint estimation of the integration orders; the third of these approaches appears to be the most tractable one. The issue of whether or not individuals are fully rational (and therefore it is legitimate to use an ex-post realization of the CPI as a proxy of the ex-ante expected inflation rate) will also be analysed in future papers.

Alternative explanations for our findings such as the decline in the marginal return of capital, tax effects, the failure to account for reverse causality, and uncertainty on the monetary policy are also very interesting avenues for future research. Finally, a deeper understanding of inflation and interest rate dynamics could be gained by testing for the existence of an international Fisher effect (i.e., the idea that economies with higher interest rates will experience a depreciation of their currency).

\section{Conflicts of interest}

No conflict of interest.

\section{Acknowledgement}

Luis A. Gil-Alana gratefully acknowledges financial support from the Ministerio de Ciencia y Tecnología (ECO2017-85503-R).

\section{Appendix A. Supplementary data}

Supplementary data to this article can be found online at https://doi.org/10.1016/j.inteco.2019.07.002.

\section{References}

Abadir, K.M., Distaso, W., Giraitis, L., 2007. Nonstationarity-extended local Whittle estimation. J. Econom. 141, $1353-1384$.

Abbritti, M., Gil-Alana, L.A., Lovcha, Y., Moreno, A., 2016. Term structure persistence. J. Financ. Econom. 14 (2), $331-352$.

Apergis, N., Christou, C., Payne, J.E., Saunoris, J.W., 2015. The change in real interest rate persistence in OECD countries: evidence from modified panel ratio tests. J. Appl. Stat. 42, 202-213.

Arteche, J., Orbe, J., 2016. A bootstrap approximation for the distribution of the local whittle estimator. Comput. Stat. Data Anal. 100, 645-660.

Baillie, R.T., Chung, C.F., Tieslau, M.A., 1996. Analysing inflation by the fractionally integrated ARFIMA-GARCH model. J. Appl. Econom. 11, 23-40.

Barkoulas, J.T., Baum, C.F., 1997. Fractional differencing modeling and forecasting of eurocurrency deposit rates. J. Financ. Res. 20, 355-372.

Barsky, R.B., 1987. The Fisher hypothesis and the forecastability and persistence of inflation. J. Monet. Econ. $19,3-24$.

Baum, C.F., Barkoulas, J., Caglayan, M., 1999. Persistence in the international inflation rates. South. Econ. J. 65, $900-913$.

Bloomfield, P., 1973. An exponential model in the spectrum of a scalar time series. Biometrika 60, 217-226.

Caporale, G.M., Pittis, N., 2004. Estimator choice and Fisher's paradox: a Monte Carlo study. Econom. Rev. 23 (1), $25-52$.

Carmichael, J., Stebbing, P.W., 1983. Fisher's paradox and the theory of interest. Am. Econ. Rev. 73 (4), 619-630.

Conti, P.L., De Giovanni, L., Stoev, S.A., Taqqu, M.S., 2008. Confidence intervals for the long memory parameter based on wavelets and resampling. Stat. Sin. 18, 559-579.

Couchman, J., Gounder, R., Su, J.J., 2006. Long memory properties of real interest rates for 16 countries. Appl. Financ. Econ. Lett. 2, 25-30.

Crowder, W.J., Hoffman, D.L., 1996. The long-run relationship between nominal interest rates and inflation: the Fisher equation revisited. J. Money Credit Bank. 28 (1), 102-118.

Crowder, W.J., Wohar, M.E., 1999. Are tax effects important in the long-run Fisher relation? Evidence from the municipal bond market. J. Financ. 54 (1), $307-317$. Cuestas, J.C., Gil-Alana, L.A., 2016. A non-linear approach with long range dependence based on Chebyshev polynomials. Stud. Nonlinear Dyn. Econom. 23 , 445-468. Dahlhaus, R., 1989. Efficient parameter estimation for self-similar process. Ann. Stat. 17, 1749-1766. 
Darby, M.R., 1975. The financial and tax effects of monetary policy on interest rates. Econ. Inq. 13, 266-269.

Davidson, R., MacKinnon, J.G., 1993. Estimation and Inference in Economics. Oxford University Press, New York.

Delgado, M., Robinson, P.M., 1994. New methods for the analysis of long memory time series. Application to Spanish inflation. J. Forecast. 13, 97-107.

de Peretti, C., 2003. Bilateral bootstrap tests for long memory: an application to the silver market. Comput. Econ. 22 (2-3), 187-212.

de Peretti, C., Siani, C., 2002. Confidence Region for Long Memory Based on Inverting Bootstrap Tests: an Application to Stock Market Indices. EPPE Working Paper

2002. University of Evry, France.

Diebold, F.X., Inoue, A., 2001. Long memory and regime switching. J. Econom. 105, 131-159.

Durbin, J., 1970. Testing for serial correlation in least-squares regression when some of the regressors are lagged dependent variables. Econometrica 38 , $410-421$.

Engsted, T., 1995. Does the long-term interest rate predict future inflation? A multi-country analysis. Rev. Econ. Stat. 77 (1), $42-54$.

Etuk, I.E., James, T.D., Asare, B.K., 2014. Fractional cointegration analysis of Fisher hypothesis in Nigeria. Asian J. Appl. Sci. 2, 1.

Evans, M., Lewis, K., 1995. Do expected shifts in inflation affect estimates of the long-run Fisher relation? J. Financ. 50, 225-253.

Fama, E.F., 1975. Short-term interest rates as predictors of inflation. Am. Econ. Rev. 65, 269-282.

Fisher, I., 1930. The Theory of Interest. MacMillan, New York.

Garbade, K., Wachtel, P., 1978. Time variation in the relationship between inflation and interest rates. J. Monet. Econ. 4, 755-765.

Geweke, J., Porter-Hudak, S., 1983. The estimation and application of long memory time series models. J. Time Ser. Anal. 4, 221-238.

Ghazali, N.A., Ramlee, S., 2003. A long memory test of the long-run Fisher effect in the G7 countries. Appl. Financ. Econ. 13, $763-769$.

Gil-Alana, L.A., 2000. Evaluation of Robinson's (1994) tests in finite samples. J. Stat. Comput. Simul. 68, 39-64.

Gil-Alana, L.A., 2004a. Long memory in the interest rates in some Asian countries. Int. Adv. Econ. Res. 9, $257-267$.

Gil-Alana, L.A., 2004b. Long memory in the US interest rate. Int. Rev. Financ. Anal. 13, 265-276.

Gil-Alana, L.A., 2004c. The use of the Bloomfield (1973) model as an approximation to, ARMA processes in the context of fractional integration. Math. Comput. Model. 39, 429-436.

Gil-Alana, L.A., 2008. Fractional integration with Bloomfield exponential spectral disturbances. A Montecarlo experiment with an application. Braz. J. Probab. Stat. 22 (1), 69-83.

Gil-Alana, L.A., Moreno, A., 2012. Uncovering the U.S. term premium.An alternative route. J. Bank. Financ. 36, 1184-1193.

Gil-Alana, L.A., Robinson, P.M., 1997. Testing of unit roots and other nonstationary hypotheses in macroeconomic time series. J. Econom. 80, 241-268.

Gilbert, C.L., Yeoward, S.M.J., 1994. Is the Fisher Effect for Real? Evidence from the UK Real and Nominal Bonds. Department of Economics, Queen Mary and Westfield College, London. Discussion Paper no. 310.

Godfrey, L.G., 1978a. Testing against general autoregressive and moving average error models when the regressors include lagged dependent variables. Econometrica 43, 1293-1301.

Godfrey, L.G., 1978b. Testing for higher order serial correlation in regression equations when the regressors include lagged dependent variables. Econometrica 43 , 1303-1310.

Granger, C.W.J., Hyung, N., 2004. Occasional structural breaks and long memory with an application to the S\&P 500 absolute stock returns. J. Empir. Financ. 11, $399-421$.

Hassler, U., 1993. Regression of spectral estimators with fractionally integrated time series. J. Time Ser. Anal. 14, 369-380.

Hassler, U., Wolters, J., 1995. Long memory inflation rates.International evidence. J. Bus. Econ. Stat. 13, 37-45.

Haug, A., 2014. On real interest rate persistence: the role of breaks. Appl. Econ. 46, 1058-1066.

Hyung, N., Franses, P.H., Penm, J., 2006. Structural breaks and long memory in US inflation rates. Do they matter for forecasting? Res. Int. Bus. Financ. 20 (1), 95-110.

Johansen, S., 1996. Likelihood Based Inference in Cointegrated Vector Autoregressive Models. Oxford University Press.

Kasman, S., Kasman, A., Turgutly, E., 2006. Fisher hypothesis revisited: a fractional cointegration analysis. Emerg. Mark. Finance Trade 42, 59-76.

Kiran, B., 2013. A fractional cointegration analysis of Fisher hypothesis. Evidence from Turkey. Qual. Quantity 47 (2), $1077-1084$.

Kumar, M.S., Okimoto, T., 2007. Dynamics of persistence in international inflation rates. J. Money Credit Bank. 39 (6), 1457-1479.

Lardic, S., Mignon, V., 2003. Fractional cointegration between nominal interest rates and inflation: a re-examination of the Fisher relationship in the G7 countries. Econ. Bull. 3, 1-10.

Lobato, I.N., Velasco, C., 2007. Efficient Wald tests for fractional unit root. Econometrica 75 (2), 575-589.

Meade, N., Maier, M.R., 2003. Evidence of long memory is short term interest rates. J. Forecast. 22, 553-568.

Mishkin, F.S., 1992. Is the Fisher effect for real? J. Monet. Econ. 30, 195-212.

Nelson, C.R., Schwert, G.W., 1977. Short-term interest rates as predictors of inflation: on testing the hypothesis that the real rate of interest is constant. Am. Econ. Rev. 67 (3), 478-486.

Phillips, P.C.B., 1998. Econometric Analysis of Fisher's Equation. Yale University. Cowles Foundation Discussion Paper \#1180.

Phillips, P.C., Shimotsu, K., 2005. Exact local Whittleestimation of fractional integration. Ann. Stat. 33, $1890-1933$.

Robinson, P.M., 1994. Efficient tests of nonstationary hypotheses. J. Am. Stat. Assoc. 89, 1420-1437.

Schmidt, P., Phillips, P.C.B., 1992. LM tests for a unit root in the presence of deterministic trends. Oxf. Bull. Econ. Stat. 54, 257-287.

Shea, G., 1991. Uncertainty and implied variance bounds in long memory models of the interest rate term structure. Empir. Econ. 16, 287-312.

Summers, L.H., 1983. The nonadjustment of nominal interest rates: a study of the Fisher effect. In: Tobin, J. (Ed.), Macroeconomics, Price and Quantities. Blackwells, Oxford, pp. 201-241.

Sun, Y., Phillips, P.C.B., 2004. Understanding the Fisher equation. J. Appl. Econom. 19 (7), 869-886.

Tsay, W.J., 2000. Long memory story of the real interest rate. Econ. Lett. 67 (3), 325-330.

Wallace, M.S., Warner, J.T., 1993. The Fisher effect and the term structure of interest rates: tests of cointegration. Rev. Econ. Stat. 75 (2), 320-324.

Woodward, G.T., 1992. Evidence of the Fisher effect from UK indexed bonds. Rev. Econ. Stat. 74 (2), 315-320. 